\title{
Study on the Role of Computers in Teaching Reform of Clothing Performance
}

\author{
Yuemei Gao ${ }^{1}$, Weiwei $\mathrm{Li}^{2}$ \\ ${ }^{1}$ Jiangxi Science \& Technology Normal University, Art College, Nanchang, Jiangxi, 330013 \\ ${ }^{2}$ Beijing Institute of Fashion Technology, School of Art and Engineering, Beijing,100029
}

Keywords: Computers, Fashion Show, Effect

\begin{abstract}
In the course of performing professional clothing reform, more and more attention to students' comprehensive ability. However, the traditional teaching fashion show there are some limitations, but will use the computer in the teaching can make up for its shortcomings, lively and dynamic, characterized by vivid fashion show teaching has injected new vitality. The basis of analyzing the traditional model of teaching process limitations, discusses the role of computers in professional clothing reform performances, including providing rich content for teaching, sharing resources and create a good atmosphere. The advantages of multimedia computer applications and the Internet play breaks through the traditional way of teaching, which is conducive to stimulate students' motivation to learn, in order to effectively improve the efficiency of teaching fashion show.
\end{abstract}

\section{Introduction}

Professional fashion show is a fusion of art and design clothing and fashion show two new professional arts of fashion, but also a function of the quality of clothing and clothing display system main research object. This profession in our institutions of higher learning established nearly 20 years, trained a lot of talent, energize the community. However, experience in the teaching process teaching system planning and inadequate allocation of educational resources asymmetry issues that hinder the sustainable development of the profession, it is difficult to meet the community for high-quality fashion show professionals demand. The computer can be text, graphics, sound and animation and other forms show in front of the image of the specific knowledge transition from abstract knowledge, which is important for the professional teaching.

\section{The Traditional Fashion Show Teaching Limitations}

In the traditional teaching process, fashion show set a single curriculum, students only learn the relevant expertise costume show, it is difficult to form the entire knowledge of the system. Setting up compulsory courses and elective courses during some messy, for the lack of cross-discipline should be combed. The professional practice has distinguished from other professional attention to the results, focusing on the nature of stage effects too much emphasis on teaching experience while ignoring systemic grasp of teaching. Course structure and content of the lack of flexibility, not conducive to the personality development of students and initiative play. Teaching the existence of practical and theoretical proportion misconfigured, theoretical training is not comprehensive training and other issues. Although students can participate in a variety of games, there are many, which makes clothing into the university students show more or less have some fashion show experience. Thus, resulting in students' professional uneven: some already have sufficient performance skills; for some professional know nothing; there already exists some of their own poor performance defects. Which are caused by the difficulty of teaching on such ideals and schools of training objectives difficult to achieve consensus. 


\section{The Computer Provides Rich Content for Teaching}

Teachers can take advantage of the unique combination of a variety of computer information, data, text, images, graphics, sound, and multimedia content in the classroom of the fashion show unfolded. At the same time, the teacher may be in the form of PPT courseware and dynamic form of animation, sound, video and other teaching full presentation content, which is different from the traditional mode of teaching. Let theoretical knowledge boring vivid display in front of students. Using computer searches the latest trends in fashion show, to get rid of outdated books on theory and case. Multi-directional guide students to obtain valuable information to enhance the ability to fashion show students access to information. In addition to basic teaching content,

During a performance practice can show 3D video on the computer to explore changes in the principles and methods change from different angles, so that will help students master the knowledge of teaching flexibility to meet the social needs of the fashion show. For the fashion show in evening dress, cheongsam performance can have the use of computer 3D presentation allows the teaching richer level, deepen the overall perception of students. For some fashion show during the visibility of the smaller operator action, you can use your computer's operating zoom, effectively break the key and difficult teaching the students to prevent the formation of the wrong perception, correct their ideas.

In a particular form of performances, for just learning this student behavior, operating skills, other precautions are not understood, and if the teacher is just teaching the traditional direct explanation, students difficult to completely understand. The computer may be some detailed knowledge in the form of video fashion show was a professor. So that students can intuitively understand the very fine details of the operation and operational processes, while allowing the student's action is more standardized. For performing the action more difficult, students can watch repeatedly, a comprehensive understanding, enable students to visual, auditory perception and overall ability to get exercise. In the process of watching the teacher reminded the students should watch where noted, those actions more difficult or easy to overlook the action. This reinforces the teacher and student interactive teaching process, achieve the purpose of happy teaching. So as to effectively enhance students' vision, hearing and general awareness. And the basics of physical training for the relevant courses and catwalk training courses, computer technology can effectively solve the traditional teaching process limitations.

\section{The Sharing of Resources for Teaching Computer}

Now is the age of the Internet, there is the advantage of rich resources on the network, in the teaching process should be fully utilized. Such as the Internet to find relevant video performance on repetitive learning or their own performance director to shoot video upload their own class, so the instructor shortage inside. You can also use the information shared on the site you can find relevant information to expand their knowledge, such as watching a big show of Victoria's Secret Mia, Milan fashion shows experience a different style of performance, performance methods, improve the aesthetic level. Or looking for online users communicate with each other to explore and improve the learning enthusiasm and initiative. Whether it is before class, lesson or class, can effectively combine the role of computers in the shared data. People from multimedia and interactive visual experience to get familiar and strange sense of fantasy, from the classroom to the school to achieve the experiential education to mobilize the enthusiasm of students and creative passion. In teaching, students focus on teamwork, mutual penetration of various disciplines, complementary advantages, so fashion show majors by a wide range of training. If you allow students to hold a fashion show, fashion show by the students to complete their own performances, invited teachers and students to watch, in the process, so that the different majors are combined to form a supportive team culture collaboration awareness and improve the overall quality of students. Computer-based multimedia platform so that more students can easily come into contact with the respective national costume for the Performing Arts, in addition to learning its essence. Coupled with the maturity and popularity of the Internet, let us more easily be able to quickly seek to fashion publishing information to keep up with the latest trends fashion show. Out 


\section{Create a Good Atmosphere for Teaching Computer}

Teaching in the clothing during performances, advocated the creation of a good learning environment for students, students of emotional health, positive attitude, correct outlook on life values, which requires attention to the teacher arranged the learning environment, with a good cultural atmosphere infected students. Because it not only reflects the spirit of the class, but also directly affect the students' psychological health. Beautiful environment in order to create beautiful soul. Although it "peaches and plums," but to make students unconsciously, naturally subject to the influence, hints and infection. The main purpose of introducing the situation is to stimulate students' interest in learning, guide students to actively participate in classroom learning. In the previous process of teaching, most teachers used in traditional instill teaching methods, teachers speak on stage, students passive acceptance, thus leading to a fashion show teaching boring stiff, narrow academic knowledge. Reducing student learning initiative. However, by operating a computer multimedia equipment, teachers will be able to show knowledge of the use of video mannequins way to show it, make it easier for students to understand. For example, in learning Chinese clothes on the stage of expression, the teacher before class so that students can enjoy a short film related to guide students to understand the origins of Chinese clothing production, development history and evolution of improvement. Fully stimulate students' interest in learning, improve student classroom participation initiative. Look on the Internet for students to experience video in top international fashion show, to create a good atmosphere, broaden their horizons, while in the process of learning gradually enhance their professional knowledge and expertise to achieve the learning objectives.

\section{Conclusion}

The computer application to the fashion show is a combination of binding one multicultural arts, and science and technology for teaching brought unlimited possibilities, visual language is a virtual image and video symbols in the fashion show, the extensive use of this inevitable choice is the era of network, network also identified modern society. Culture and fashion, performing arts clothing comes from life, but also higher than life. The network better to lead the popular aesthetic appeal, the computer allowed to intervene in the context of the information society to find a new form of performance and art forms. Understand the intent of curriculum reform, teaching research strategies focus on improving their overall quality. Teaching is a fashion show in the ongoing reforms process in the formation of the traditional teaching model, not only will the quality of education throughout the teaching, but also on the knowledge of systematic, theoretical, practical. Not just the future, computer applications can better play a better role in the reform of professional clothing performances.

\section{Acknowledgements}

Doctor Scientific Research Fund Project of Jiangxi Science \& Technology Normal University Film Industry in China since the Reform and Opening and Countermeasures.

Fund projects: 15324 Research Program - College fashion show teaching practice management software development.

\section{References}

[1] Li Danqi. Introduction to Clothing [M]. Beijing: Higher Education Press, 2002.

[2] Yan Xia. Study ways and means of multimedia technology in teaching. Packaging World, 2013 (6).

[3] Deng Xianfeng. Multimedia technology in clothing curriculum teaching. Scientific Advisory (late), 2011 (8). 